\title{
Optimal Vector Control Of Kite Tethers For Maximum Power Extraction From High Altitude Winds \& Kite Designing
}

\author{
Bongu Chandrashekar ${ }^{1}$, Anirudh Kasavaraju ${ }^{1}$, Dr.R. Saravanakumar ${ }^{2}$ \\ ${ }^{1}$ Students of Control and Automation, M-Tech, VIT, Vellore, 632014, Tamil Nadu. \\ ${ }^{2}$ Professor, SELECT, VIT, Vellore, 632014, Tamil Nadu.
}

\begin{abstract}
High altitude power generation using kites is a method of harvesting wind power using tethered kites at high altitudes. The present wind turbines used for wind power generation which are placed at a height of 200 to $300 \mathrm{ft}$ above the ground where the wind speed is not high and are highly variable. So power generation using kites helps us to generate power from the winds which have high velocity and are highly predictable at high altitudes. In this paper we will discuss about the designing of the kite through software and finding the algorithm for the parafoil kite using optimal vector method to extract maximum power from the wind as well as kite designing.
\end{abstract}

\section{Introduction}

In India wind power accounts for 14 per cent of the total installed power capacity but the electric power produced in India from the wind is less than 5 per cent. It's because wind turbines do not rotate continuously because of the unavailability of constant wind at that height. In order to meet the increasing power demand daily huge amount of fossil fuel is being burnt causing a great concern to our environment. So scientists are trying to find out a novel method to produce power from renewable sources such as wind, solar, geothermal etc. the present scenario in power generation is that wind turbines used in wind power generation are unable to meet the growing demands of the power as the traditional wind turbines which are at a height of 150 to $200 \mathrm{ft}$ above the ground are unable to capture huge amount of power as wind at that height is not constant and predictable. So in order to get power from high speed winds we must move to higher altitudes. One of the method to capture wind from high altitude wind is by using kites. So in this paper we shall be dealing with the optimal vector control of kite tethers to extract maximum power from the wind. Winds at high altitude keep varying so we need to adjust the angle of attack to get the desired output power from the kite. Here we are adjusting the angle of attack using servo mechanism.

\footnotetext{
${ }^{1}$ Corresponding author: cnani39@gmail.com
} 
This paper deals with the modelling of kite and designing the p,pi,pid controller for the servo motor. In this paper we shall be designing the kite model with required parameters.

\section{Key technology}

From Fig. 1 and 2 we can see that a para-foil kite is being implemented where two cables are connected to the two ends of the kite[1,2]. The other two ends are connected to the rotor (gears) of the generator present at the ground. In this technique, we fly the kite at a height which is more than 300 metres above the ground.

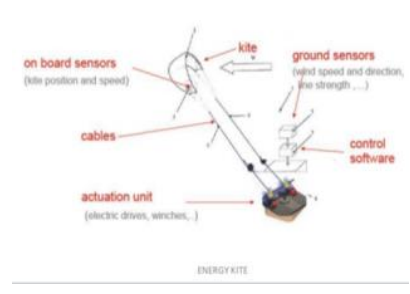

Fig 1. Key technology of kite.

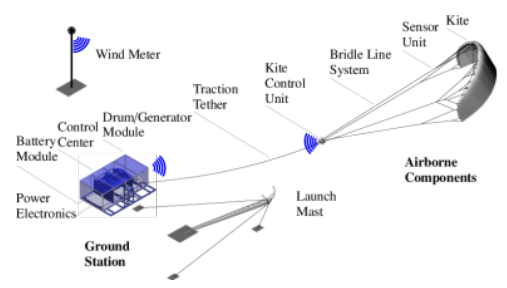

Fig 2: Components of kite electric power plant.

At this point, the surface of the kite is perpendicular to the direction of the wind, hence maximum force is exerted by the wind on the kite which pushes the kite to further high altitude. The force with which the kite is pulled by the wind is enough to rotate the generators present at the ground with the help of cables connecting the kite. After the kite reaches to a height of more than 900 meters above the ground the sensor sends signal to the control unit which is present at the ground. At that point, one of the cable will be stopped and the other one will be made to move with the help of gears which are placed with the control unit. Since, one cable becomes stationary and other one is loosened the kite moves in such a way that the surface of the kite becomes parallel to the direction of the wind, so the force exerted on the kite will be minimum, at this point of time the generator present $t$ the ground can be used as a motor to pull back both the cables at a time. The force exerted by the wind on the kite will be less so the energy required to pull back the kite will be very less i.e. almost a fraction of energy from the generation phase. So, the kite is pulled back towards the ground till it reaches 300meters then again with the help of gears we will bring back the loosened cable to its original position i.e. the surface of the kite again becomes perpendicular to the direction of the wind then again the mechanism which is described earlier will start and this mechanism will be continuously operated in order to get continuous energy.Here in this mechanism we are using the generator for both motoring and generating mode. We shall be using 4 tether to control angle of attack of para foil kite. We shall be placing servo motors at each end of the tether at either at the surface or at the kite knot depending on our condition. Depending on the velocity of wind we shall be adjusting the tethers of the kite to extract rated power of the generator[2,4,6].

With the equations we can calculate the angle of attack from the height of the kite. We shall also place the wind sensors on the kite to estimate the wind speed.

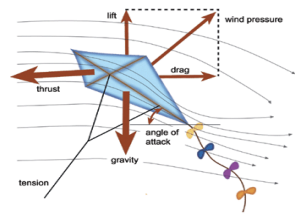

Fig. 3. Forces acting on kite. 
The force of the wind acting on the kite can be resolved into two components one being the drag component which is the horizontal component and the other being the lift which is the vertical component. The weight due to gravity can null in this condition.

$$
\text { Lift }=1 / 2\left(C_{L} \text {.D.A. } V^{2} \cos ^{2}(x)\right)
$$

Where $\mathrm{C}$ is the lift power coefficient and $\mathrm{D}$ is the density of the air which is generally assumed to be one. $\mathrm{C}$ is the lift power coefficient which will be lower if the angle of attack will be greater than 15 degrees.

$$
\text { Drag }=1 / 2\left(C_{d} \cdot D \cdot A^{2} \sin ^{2}(x)\right) .
$$

Where $C_{d}$ is coefficient of drag power which is approximately equal to 2 .

$$
\mathrm{P}=1 / 2\left(\mathrm{C}_{\mathrm{L}} \cdot \mathrm{D} \cdot \mathrm{A} \cdot \mathrm{V}^{3} \cos ^{3}(\mathrm{x})\right)+1 / 2\left(\mathrm{C}_{\mathrm{d}} \cdot \mathrm{D} \cdot \mathrm{A} \cdot \mathrm{V}^{3} \sin ^{3}(\mathrm{x})\right)
$$

We shall take a generator which has a power ration of $\mathrm{P} 1$. The wind can have sometimes very high speed because of which the power produced will be higher than the rated power of the generator. So as per the wind we must adjust the angle of attack. So equate the equation of power generated from kite to the rated power of the generator.

$$
\left.\left.\mathrm{P} 1 /\left(1 / 2 * \mathrm{D} * \mathrm{~A} * \mathrm{~V}^{3}\right)=\mathrm{C}_{\mathrm{L}} \cdot \cos ^{3}(\mathrm{x})\right)+\mathrm{C}_{\mathrm{d}} \sin ^{3}(\mathrm{x})\right)
$$

We must solve the equation to get the angle of attack. Or solve for angle of attack we can use a for loop in MATLAB or any other software to equate each value of x from 0 to 90 to check at which point the given equation will satisfy the condition.

After solving for $\mathrm{x}$ we should calculate the length of the wire to be loosened or tightened so as to adjust the kite angle of attack. So that we can give the length to the servo motor which will loosen or tight the string depending upon the input. We can calculate the length of the string to be adjusted from the sine rule of the triangle.

$$
\mathrm{a} / \sin (\mathrm{A})=\mathrm{b} / \sin (\mathrm{B})=\mathrm{c} / \sin (\mathrm{C})
$$

Table 1. Different angle of attack for different wind speeds.

\begin{tabular}{|l|l|l|l|l|}
\hline $\begin{array}{l}\text { Availble } \\
\text { Wind } \\
\text { speed in } \\
\mathrm{m} / \mathrm{s}\end{array}$ & $\begin{array}{l}\text { Rated } \\
\text { power of } \\
\text { generator } \\
\text { in watts }\end{array}$ & $\begin{array}{l}\text { Power } \\
\text { which } \\
\text { can be } \\
\text { extracted }\end{array}$ & $\begin{array}{l}\text { Angle } \\
\text { of } \\
\text { attack } \\
\text { in } \\
\text { degrees }\end{array}$ & $\begin{array}{l}\text { Available } \\
\text { wind } \\
\text { power } \\
\text { in W }\end{array}$ \\
\hline 5 & 1250 & 1237 & 85.0 & 1250 \\
\hline 5.3 & 1250 & 1279 & 69.34 & 1488 \\
\hline 5.5 & 1250 & 1263 & 63.68 & 1663 \\
\hline 5.9 & 1250 & 1239 & 55.14 & 2053 \\
\hline 6.1 & 1250 & 1211 & 51.59 & 2269 \\
\hline 6.3 & 1250 & 1179 & 48.33 & 2500 \\
\hline
\end{tabular}

\section{Kite design}

In this paper, we have modelled parafoil kite with the help of CAD package CATIA V5. In addition to this, we have done numerical analysis for wind energy generation of parafoil kite in ANSYS software. We have make use of CATIA V5 for designing and modelling of parafoil kite. The coordinates used for modelling of kite is took from NACA standards. The original design of aerofoil is shown in Fig 4. 


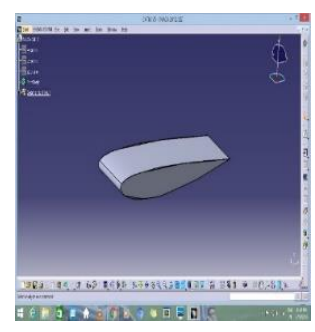

Fig. 4. Original Aerofoil Design.

We have made use of NACA standard and took NACA 4-digit parameter for designing of parafoil kite. We had made use of NACA 2412 standard for the modelling. The NACA 2412 aerofoil has got $2 \%$ of maximum camber. Using CATIA V5, two designs of parafoil kite has been obtained which are shown in Fig 5.
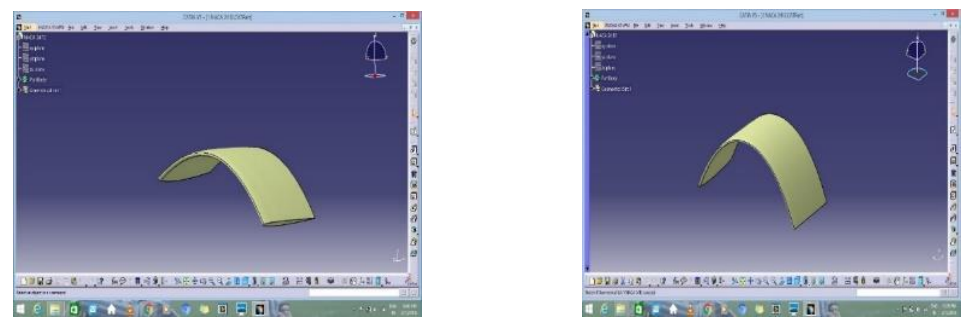

Fig. 5. Half circled and Semi circled Kite.

\section{Aerodynamic simulation}

ANSYS version 16 is used for simulation purpose [3, 5] and CATIA V5 is used for designing of kite. Standard coordinates had been taken by NACA. Now, we had imported to ANSYS (.stp file) for meshing, plotting of coefficient of drag and lift, and various simulations of effect of wind on kite. Fig 5(Half Circled) shows the geometry used for simulation. Fig 6 shows the steps which were involved in ANSYS for modelling the kite.

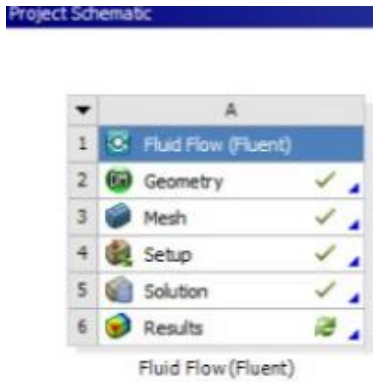

Fig. 6. Steps in ANSYS Environment 


\section{Graphs \& simulation results}
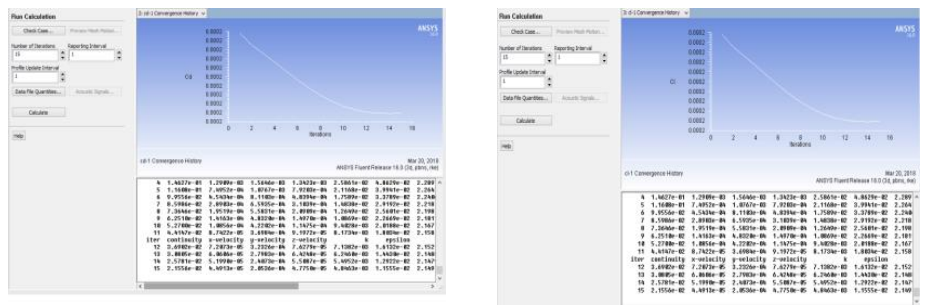

Fig. 7. (a) Coefficient of Drag; (b) Coefficient of Lift

Here, in this simulation we assumed input velocity as $10 \mathrm{~m} / \mathrm{s}$ for every outcome.

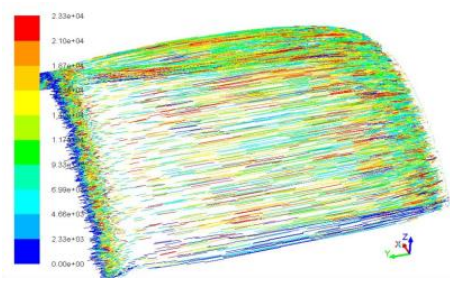

Fig. 8. Path lines coloured by Particle ID (pascals).

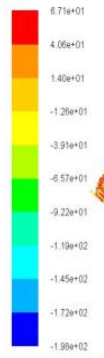

Fig. 10. Velocity Vector

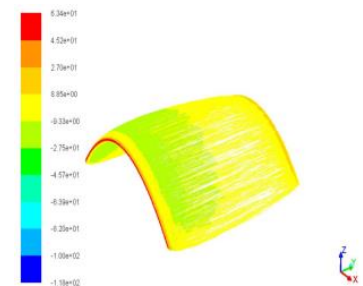

Fig. 9. Path Lines coloured by Static Pressure

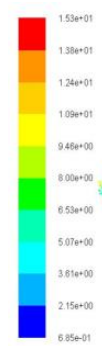

$\sum_{x}$

Fig. 11. Velocity Vector coloured by velocity magnitude

(in $\mathrm{m} / \mathrm{s}$ )

Vector coloured by static pressure is shown in Fig 10 which shows how the wind enters and how the wind leaves the path. Fig 11 shows the velocity vector coloured by velocity magnitude (in $\mathrm{m} / \mathrm{s}$ ).In this way, we have done some aerodynamic analysis and got the simulation results for inlet velocity $=10 \mathrm{~m} / \mathrm{s}$.

\section{Conclusion}

Hence by using the optimal vector control of tethers we can control the power generated from the kites at high altitudes by changing the angle of attack with the help of servo motor. 


\section{References}

1. H. Zhang, Energy and Power Engineering, 5, 481-488, 2013.

2. U. Fechner, A Methodology for the Design of Kite-Power Control Systems, Delft University of Technology, (2016)

3. R. Castelino, S. Jana, and R. Kumar. International Journal of Electronics, Electrical and Computational System, 6, 33-38, (2017).

4. J. Zhang, M. Cheng, Z. Chen, X. Fu, 2008 Third International Conference on Electric Utility Deregulation and Restructuring and Power Technologies, Nanjing, 2691-2696, (2008).

5. H. Zhang, Energy and Power Engineering, 5, 481-488 (2013).

6. L. Fagiano, M. Milanese, D. Piga, TechConnect World Conference and Expo 2010, Anaheim (California), USA, (2010).

7. H. Zhang, Energy and Power Engineering, 5, 481-488, (2013).

8. J. Adhikari, I V. Prasanna, S K. Panda, 2015 IEEE 11th International Conference on Power Electronics and Drive Systems, Sydney, NSW, 773-778, (2015). 